AIAA-2001-1466

\title{
TEST CASES FOR MODELING AND VALIDATION OF STRUCTURES WITH PIEZOELECTRIC ACTUATORS
}

\author{
Mercedes C. Reaves* and Lucas G. Horta** \\ NASA Langley Research Center \\ Hampton, Virginia
}

\begin{abstract}
A set of benchmark test articles were developed to validate techniques for modeling structures containing piezoelectric actuators using commercially available finite element analysis packages. The paper presents the development, modeling, and testing of two structures: an aluminum plate with surface mounted patch actuators and a composite box beam with surface mounted actuators. Three approaches for modeling structures containing piezoelectric actuators using the commercially available packages: MSC/NASTRAN and ANSYS are presented. The approaches, applications, and limitations are discussed. Data for both test articles are compared in terms of frequency response functions from deflection and strain data to input voltage to the actuator. Frequency response function results using the three different analysis approaches provided comparable test/analysis results. It is shown that global versus local behavior of the analytical model and test article must be considered when comparing different approaches. Also, improper bonding of actuators greatly reduces the electrical to mechanical effectiveness of the actuators producing anti-resonance errors.
\end{abstract}

\section{INTRODUCTION}

NASA Langley Research Center, Industry and Academia have been actively studying and developing induced strain actuation devices for aircraft and aerospace applications since the late $1980^{\prime} \mathrm{s}^{1-2}$. Induced strain actuation is the process by which commanded strain in some elements of a structure induces deformation of the overall structure. Strain actuation such as thermal expansion and piezoelectricity ${ }^{3}$ involves strain components other than those caused by stress. Piezoelectric materials such as Lead

\footnotetext{
* Research Engineer, Structural Dynamics Branch

** Assistant Head, Structural Dynamics Branch

'This paper is declared a work of the U.S. Government and is not subject to copyright protection in the United States.
}

Zirconate Titanate (PZT) ceramics when subjected to an electric field produce mechanical strain or alternately generate an electric charge when subjected to a mechanical strain. This property gives piezoelectric materials the ability to act as actuators or sensors. Using piezoelectric actuators and sensors to form self-controlling and self-monitoring systems to improve performance of aircraft and space structures has attracted interest in the research community.

Numerous researchérs have developed analyses and models for piezo-electrically controlled structures. Some of these studies include: a high-order theory to model composite laminates with surface bonded or embedded piezoelectric sensors and actuators including pre-existing debonding by Seely ${ }^{4}$; a three-dimensional finite element code which includes incompatible modes to analyze the mechanical-electrical response of laminated composites containing distributed piezoelectric ceramics developed by Sung $\mathrm{Kyu} \mathrm{Ha}^{5}$; the use of classical laminate theory to estimate the through-the-thickness strain distribution of composite laminates with embedded actuators by Crawley ${ }^{6-7}$ and others $^{8-9}$. Although those analytical techniques showed good correlation with experimental data, they can be complicated and difficult to implement even for simple structures.

Due to the increasing interest in the design of complex structures with piezoelectric actuators and the need for fast and simple implementation of piezoelectric control systems, major FEM code developers have incorporated or provided the tools to create piezoelectric elements. Freed $^{10}$ developed one and two-dimensional finite elements which include piezoelectric coupling for integration into MSC/NASTRAN. Hauch ${ }^{11}$ investigated using ABAQUS electromechanicalcoupled finite elements and superelement capabilities for modeling structures with piezoelectric actuators. These advances in the modeling capabilities of piezoelectric actuators have allowed a number of viable analytical and numerical tools. Still, there is a demand for improvement in the modeling tools and veryimportantly a need for an experimental database for validation. 
It is the goal of the present research to develop a set of benchmark test article structures to validate techniques for modeling structures containing piezoelectric actuators using commercially available FEA packages. The paper presents the development, modeling, and testing of two structures: an aluminum plate with surface mounted patch actuators and a composite box beam with surface mounted actuators. Three approaches are presented for modeling structures containing piezoelectric actuators using the commercially available packages MSC/NASTRAN and ANSYS.

The first approach uses MSC/NASTRAN to model the structure with piezoelectric actuators and a thermally induced strain to model straining of the actuators due to an applied voltage field. To reduce the number of structural modes needed for an accurate solution, Ritz vectors are appended to the structural modes. This approach was proposed in Ref. 12 and was shown to be very effective in capturing local effects with reduced order models. A second approach involves the development and integration of one-dimensional and two-dimensional piezoelectric finite elements into MSC/NASTRAN using the dummy element capability. The constitutive equations for piezoelectric elements are implemented as FORTRAN modules linked to MSC/NASTRAN executable program. The user addresses the piezoelectric elements in the same manner as standard elements. The third approach uses conventional finite element techniques with piezoelectric coupled field elements offered in ANSYS. The approaches, applications, and limitations are discussed. Data for both test articles are compared in terms of Frequency Response Functions (FRFs) from deflection and strain data as a function of input voltage to the actuator.

\section{TEST ARTICLES AND TESTING PROCEDURES}

\section{Aluminum beam test article}

A cantilevered aluminum beam 2.75 " x 16" x .04" (figure la) with one piezoelectric actuator bonded near the root is constructed. The instrumentation is shown in figure (1b). A Flex-Patch piezoelectric actuator, developed and fabricated at NASA LaRC, is selected for the application. The Flex-Patch consists of a 3"x1.75"x.008" Morgan Matrox PZT-5A ${ }^{13}$ piezoceramic encapsulated using a polymer film. The PZT-5A piezoceramic mechanical and electromechanical properties are listed in Table 1. The electro-mechanical device undergoes a dimensional change when an electric voltage is applied imparting a stress to the surface ${ }^{14}$. In this mode, the strain actuator can be used as an actuator or sensor for the control of structural dynamics. A non-contacting proximity sensor is used to measure out-of -plane deflections and a strain gage measures longitudinal strain resulting from bending actuation. Frequency response functions from deflection and strain data as a function of input voltage to the actuator are obtained in the frequency range between 1 and $500 \mathrm{~Hz}$.

\section{Composite box beam test article}

In an effort to explore a more complex structure, a $5 \mathrm{ft}$ long T300/976 graphite-epoxy composite box beam with a $0.75^{\prime \prime} \times 3.0^{\prime \prime}$ hollow rectangular cross section, a wall thickness of $0.03^{\prime \prime}$ and laminate layout $\left[45^{\circ},-45^{\circ}\right.$, $0^{\circ} \mathrm{J}_{\mathrm{S}}$ is constructed, figure 2a. Two actuators are surface-mounted back-to-back near the root for bending actuation. Figure $2 b$ shows a photograph of the instrumented box beam and test set-up. The material properties of the composite (T300/976) are listed in Table 1.

\section{Actuator bonding}

Many applications of piezoelectric actuators require the device to be attached to the surface of the structure. Piezoelectric actuators must transmit mechanical energy to and from the structure. Therefore, proper attachment of the actuator to the structure is critical. Two widely used methods to bond the actuators to a surface are investigated. The first technique referred in this paper as the v-bond technique, involves attaching a Flex-Patch actuator to the aluminum beam specimen using a thin layer of a two-part epoxy and applying 14.5 psi in a vacuum bag while curing for 24 hrs. The second technique ( $p$-bond technique) uses the same adhesive and $1 \mathrm{psi}$ is applied to the actuator under ambient conditions and left to cure for $24 \mathrm{hrs}$. Frequency response functions from deflection and strain data as a function of input voltage to the actuator are used for comparison of actuator effectiveness on the aluminum beam for the two different bonding techniques.

\section{MODELING APPROACHES}

Thermal Strain Analogy

MSC/NASTRAN, one of the most widely used commercially available FEA codes, offers no piezoelectric coupled-field elements with which to model smart structures directly. Rather, the analogy between piezoelectric strain and thermally induced strain, which allows temperature change to model piezoelectric voltage actuation is used. Piezoelectric coefficients characterizing the actuator are input as thermal expansion coefficients (CTE's) associated with standard elements. For the present study the model treats both the actuator and the structures substrates as plies of an integrated laminated plate. PCOMP cards in 
MSC/NASTRAN are used to specify the properties of the composite lay-up and the applied voltage is modeled as a thermal load. Generally, static voltage actuation and modal analysis can be performed regardless of the number of degrees of freedom in the model. Transient and frequency response analyses types in MSC/NASTRAN are computationally intensive for large models. However, an alternative is to model the low frequency dynamics of the piezo actuated structure using the model reduction technique described in reference 12 . Ritz vectors are computed for each actuator using a thermal load equivalent to 1 volt. A general eigenvalue/eigenvector MSC/NASTRAN solution containing special structural matrices transformation routines (DMAP) combine the Ritz vectors and eigenvectors and calculates the mass and stiffness matrices needed to assemble the reduced order model. The reduced mass and stiffness matrix are output by NASTRAN DMAP sequence in ASCII format, and a punch file with the displacements for the structural modes including the Ritz vectors is also generated. MATLAB scripts are required to assemble the dynamic equation and generate frequency response function at the locations of interest.

Piezoelectric element implementation in UserModifiable MSC/NASTRAN

The User Modifiable option in MSC/NASTRAN allows for addition of user created elements, called 'dummy' elements for modeling piezoelectric structural members. MRJ Technologies developed and integrated a one-dimensional and two-dimensional piezoelectric finite elements into MSC/NASTRAN using the dummy element capability ${ }^{10}$. The constitutive equations for piezoelectric elements are implemented as FORTRAN modules linked to MSC/NASTRAN executable program and the piezoelectric elements are used in the same manner as standard elements. In this study the MRJ 4-node quadrilateral piezoelectric element (VQCT4) is selected to model the areas on both test articles that contain piezoelectric actuators. VQCT4 are two-dimensional Reissner-Mindlin, equivalent single layer (ESL) elements with a voltage degree of freedom. The non-piezoelectric portion of the structure is modeled using conventional 4-node (CQUAD4) elements with composite material properties. Under a NASA LaRC contract, MRJ technologies developed a PATRAN GUI for pre and post-processing the MRJ piezoelectric element. The solution and model reduction follow the procedure described in the previous section.

\section{ANSYS piezoelectric element}

ANSYS/Mechanical finite element program offers two and three dimensional piezoelectric coupled-field elements for modeling structures with piezoelectric actuators/sensors. Included are static, modal, full harmonic and transient analysis. ANSYS also provides a pre-processing capability for geometry and FEM mesh creation. The main difficulty users encountered when using ANSYS is the conversion of the piezoelectric strain based manufacturer's material data into the stress based format required by ANSYS. As an aide to ANSYS users, a macro 'PIEZMAT' which can be invoked from the command line, is available to convert the manufacturer's data into ANSYS form. Still, the user needs to verify and have a complete understanding of the converted data. After the FEM mesh and material properties are defined, any of the available solutions mentioned earlier can be used. For the current application SOLID5 3-D coupled-field solid elements are used to model the piezoelectric layers/components and conventional SOLID45 or SOLID 46 (layered composites) 3-D solid brick for the non-piezoelectric portion of the test structures. Frequency response functions are generated from a full harmonic analysis. For some applications, depending on the number of degrees of freedom in the model, the full harmonic solution might not be possible due to computer resources limitations.

\section{DISCUSSION OF RESULTS}

The first test article studied is the aluminum beam. The frequency response functions for input voltage, tip displacement, and strain gage data are generated from analysis and testing. NASTRAN analysis results using the first modeling technique are shown in Fig. 3 for the first four beam/actuator mode shape deformations with corresponding frequencies of 5.68, 33.59, 60.24 and $91.21 \mathrm{~Hz}$. To examine the input/output relationship of the system with the actuator, Fig. 4 shows a comparison of the frequency response function magnitude (top) and phase (bottom) from the beam tip displacement to the piezo-actuator input voltage. Analysis results for the thermal MSCNNASTRAN and MSC/NASTRAN piezoelectric element techniques are identical and are shown by the solid line, ANSYS results are shown by the dotted line and experimental results are shown dashed. The frequency response functions from all three analysis approaches show similar testanalysis correlation. Correlation of test and analysis is excellent when examining the global displacement of the beam, steady-state displacement and resonance frequencies predicted within $1 \%$ and $8 \%$ respectively. Figure 5 shows results from the nearly collocated strain gage. In this case, although the poles (resonant peaks) are in agreement with the test, the zeros of the transfer function are not. The data also shows slight phase delays due to strain gage control electronics (not accounted for in the analytical model). Experimentally discrepancies in the zero locations are attributed to two 
main factors: sensitivity of sensor location and potential de-bonding of the piezo-actuator. Since strain gage information provides for a better description of the local strain field near the actuator, small discrepancies in the gage location between the model and the test article causes significant errors in the zero locations. In addition, if actuator de-bonding occurs or if the actuators are improperly bonded to the structure, this amounts to an actuator shape change and significant errors in the zero location.

Figure 6 shows a comparison of actuator effectiveness on the aluminum beam for the two different bonding techniques discussed earlier. The strain gage results (top figure) show reductions in electrical to mechanical effectiveness of $64 \%$. Displacement results (bottom figure) show reductions of $50 \%$.

Frequency response functions for input voltage, tip displacement, and strain gage data are also generated from analysis and testing of the composite box beam. The first four predicted beam/actuator mode shapes are shown in Figure 7. Figures 8 and 9 show correlation of test and analysis frequency response functions for the box beam tip displacement and the nearly collocated strain gage. In this case, low frequency resonance are predicted within 12 and $13 \%$ and anti-resonance show errors up to $16 \%$. Despite the complexity of the structure, the results follow similar trends to those found for the baseline test article, good correlation for global behavior and discrepancies in the zero locations for localized effects. The frequency response functions from the basic MSC/NASTRAN thermal analogy/Ritz vector technique and the MSC/NASTRAN twodimensional piezoelectric element technique are identical. A $10 \%$ difference between the frequencies predicted using MSCNNASTRAN techniques and ANSYS can be attributed to geometrical details (cross section fillets) included in the ANSYS solid model. Even though the three different analysis approaches provided comparable test/analysis results, the need for DMAPs for model reduction for the thermal analogy MSC/NASTRAN modeling technique, the cost of the User Modifiable MSC/NASTRAN module and use of DMAPs for model reduction for the MRJ piezoelectric element technique, and model size limitations due to full solution in ANSYS, are computational issues that need to be considered well.

\section{CONCLUDING REMARKS}

Two test articles of increasing complexity have been developed and tested for validation of commercial analysis tools. Three approaches for modeling structures containing piezoelectric actuators using the commercially available packages: MSC/NASTRAN and ANSYS have been studied. The approaches, applications, and limitations are discussed. The results highlight some fundamental issues associated with the modeling and validation of structures with piezoelectric actuators: 1) Global behavior of structures with piezoelectric elements is relatively simple to obtain accurately, whereas local behavior near the actuator is not predicted as well. 2) When comparing analytical models to test, the zeros of the transfer function are very sensitive not only to sensor location but also to bond effectiveness and Ritz vectors convergence 3 ) Improper bonding of actuators can greatly reduce the electrical to mechanical effectiveness of the actuators. Anti-resonance errors of up to $16 \%$ can be attributed to potential de-bonding and/or sensitivity of the strain gage. 4) Frequency response function results using the three different analysis approaches provided similar test/analysis results. Still, the need of DMAPs for model reduction for the basic MSCNASTRAN modeling technique, the cost of the User Modifiable MSCINASTRAN module and use of DMAPs for model reduction for the piezoelectric element technique, and model size limitations due to full solution in ANSYS, are limitations to implementation in large systems.

\section{REFERENCES}

1. Crawley E.F., "Intelligent Structures for Aerospace: A Technology Overview Assesment". AIAA Joumal, Vol. 32, No. 8 , August 1994.

2. Bailey, T. L., and Hubbard, J.E., "Distributed Piezoelectric-Polymer Active Vibration Control of a Cantilever Beam". Journal of Guidance, Control, and Dynamics, Vol.8, Sept.-Oct. 1985, pp. 605611.

3. Crawley, E. F. and de Luis J., "Use of Piezoelectric actuators as Elements of Intelligent Structures". AIAA Journal, Vol. 25, No. 10, 1987, pp. 13731385.

4. Seeley, C. E. and Chattopadhyay, A., "Analysis of Smart Composite Structures Including Debonding". Ph. D. Dissertation, Arizona State University, May 1997.

5. Ha, S. K., Keilers, C., Chang, Fu-Kuo, “ Finite Element Analysis of Composite Structures Containing Distributed Piezoceramic Sensors and Actuators". AIAA Joumal, Vol. 30, No. 3, March 1992.

6. Crawley E. F., and Lazarus, K. B., "Induced Strain Actuation of Isotropic and Anisotropic Plates". AIAA Joumal, Vol. 29, No. 6, June 1991. 
7. Crawley, E.F., and Anderson, E. H., “ Detailed Models of Piezoelectric Actuation of Beams". Joumal of Intelligent material Systems and Structures, Vol. 1, January 1990, pp. 4-25.

8. Lam, K.Y., Peng, X. Q., Liu G.R. and Reddy, J.N., " A Finite-element Model for Piezoelectric Composite Laminates". Smart Materials and Structures 6 (1997) 583-591.

9. Won, C.C., Sulla, J.L., Sparks, D.W., Belvin, W.K., "Application of Piezoelectric Devices to Vibration Suppression". Journal of Guidance, Control, and Dynamics, Volume 17, Number 6, Pages 1333-1338.

10. Freed, B.D, Babuska, V., "Finite Element Modeling of Composite Piezoelectric Structures with MSC/NASTRAN". SPIE's $4^{\text {th }}$ Annual Symposium on Smart Structures and Materials, San Diego, CA. Paper 3041-60.
11. Hauch, R. M., "ABAQUS Smart Structure Modeling Methods". AMS-TN-95-02, February 21, 1995.

12. Sandridge, C. A. and Haftka, R. T., " Accuracy of Eigenvalue Derivatives from Rediuced-Order Structural Models". Joumal of Guidance, Control and Dynamics, Vol. 12, No. 6, Nov.-Dec. 1989.

13. Berlincourt, D. and Krueger, H.A., "Properties of Morgan ElectroCeramic Ceramics". Technical Publication TP-226. Morgan ElectroCeramics, 2000.

www.morgan electroceramics.com/techpubl.html

14. Jaffe, B. and Cook Jr., W.R., and Jaffe, H., "Piezoelectric Ceramics". Gould Inc., Cleveland Ohio,U.S.A. 44108.1971.

\section{TABLES}

Table 1. Material properties of PZT-5A piezoceramic and T300/976 graphite/epoxy composite

\begin{tabular}{|c|c|c|}
\hline & PZT-5A & T300/976 \\
\hline Modulus of elasticity $\left(\mathrm{lb}_{f} / \mathrm{in}^{2}\right)$ & & $2.17 \mathrm{E}+7$ \\
\hline $\mathrm{E}_{1}$ & $1.0 \mathrm{E}+7$ & $1.305 \mathrm{E}+6$ \\
\hline $\mathrm{E}_{2}$ & & 0.3 \\
\hline Poisson's ratio & 0.3 & \\
\hline$v$ & & $1.03 \mathrm{E}+6$ \\
\hline Shear Modulus $\left(\mathrm{lb}_{f} / \mathrm{in}^{2)}\right.$ & $3.82 \mathrm{E}+6$ & $1.03 \mathrm{E}+6$ \\
\hline $\mathrm{G}_{12}$ & & 363600 \\
\hline $\mathrm{G}_{12}$ & & \\
\hline $\mathrm{G}_{22}$ & & $1.49 \mathrm{E}-4$ \\
\hline$\rho$ & $7.16 \mathrm{E}-4$ & \\
\hline Density, $\left(\mathrm{lb}_{f}-\mathrm{sec}^{2} / \mathrm{in}^{4)}\right.$ & & \\
\hline $\mathrm{Piezoelectric} \mathrm{constant,} \mathrm{(in/Volt)}_{\mathrm{d}_{31}}$ & $6.73 \mathrm{E}-9$ & \\
\hline Electrical permitivity, (farads/in) & & \\
\hline$\xi^{\delta}$ & $4.2 \mathrm{E}-10$ & \\
\hline
\end{tabular}




\section{FIGURES}

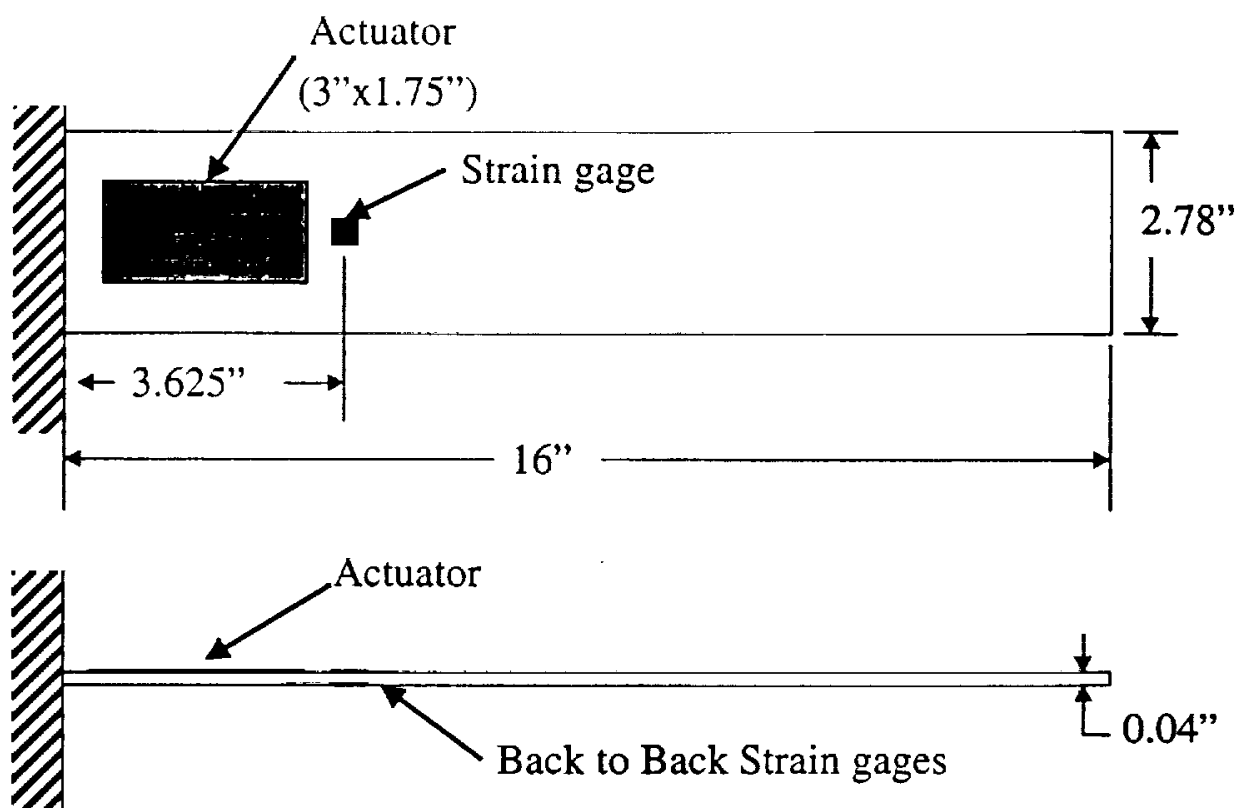

Figure 1a. Aluminum beam sketch.

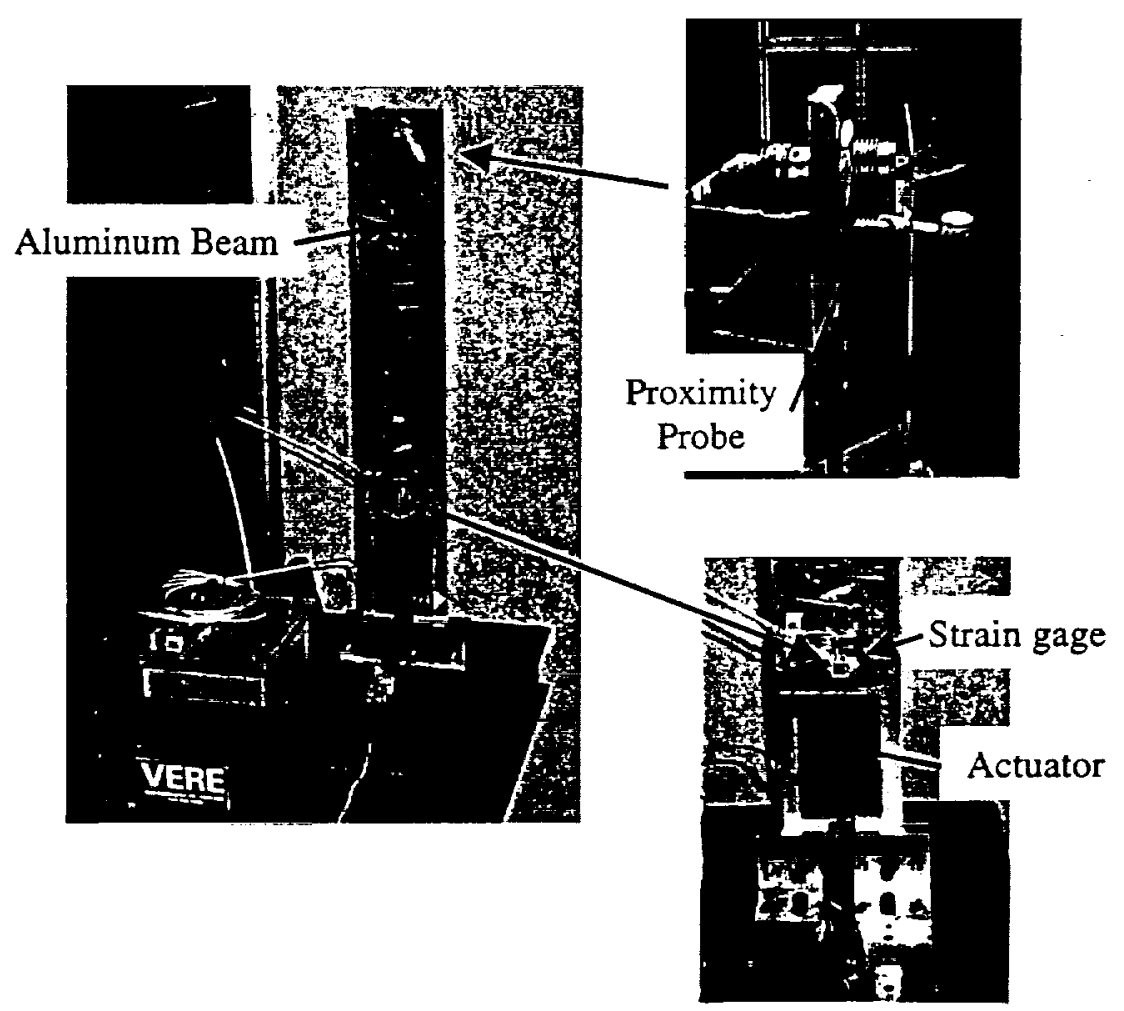

Figure lb. Photograph of instrumented aluminum test article. 

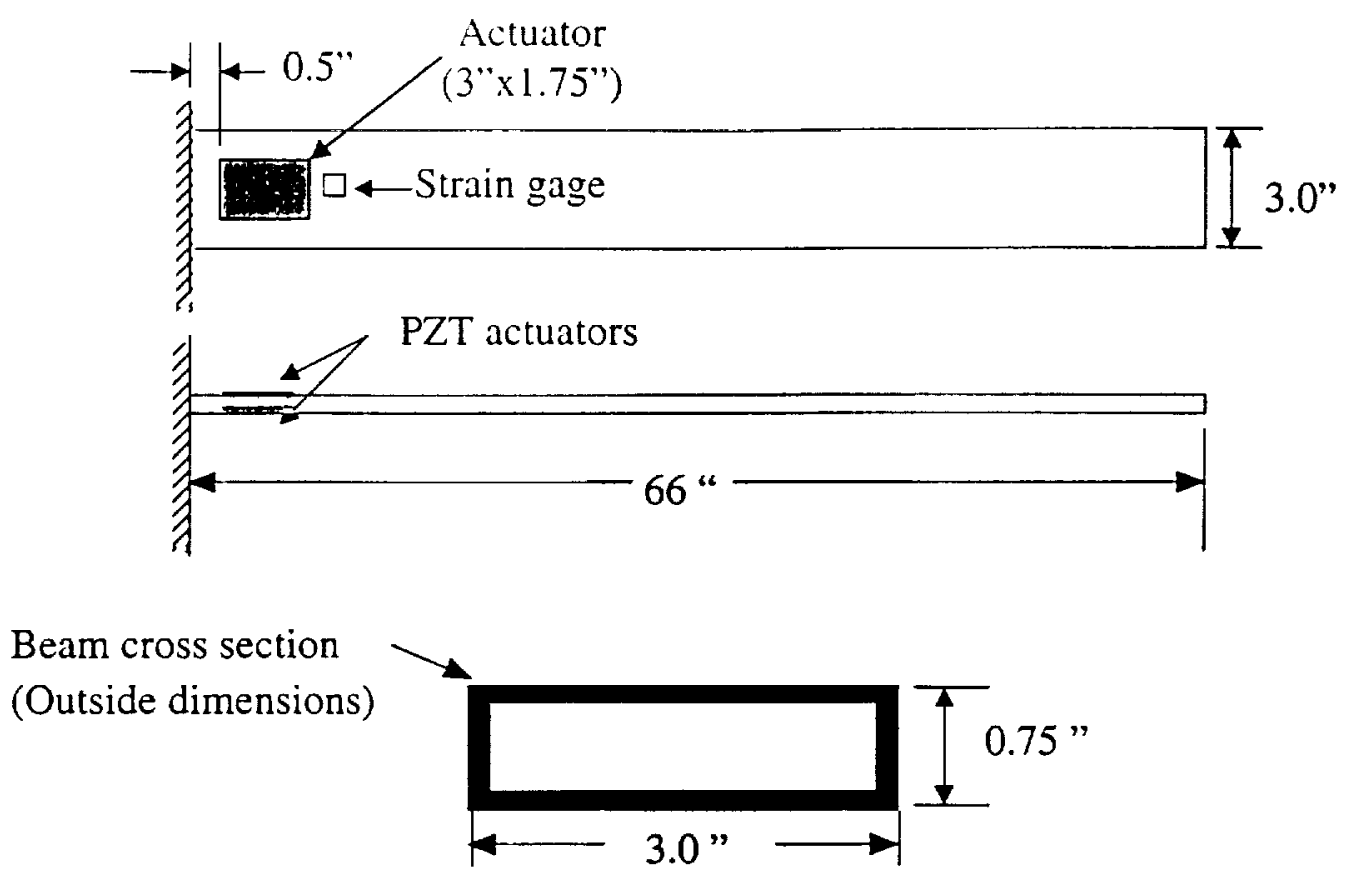

Figure 2a. Composite Box Beam Sketch.

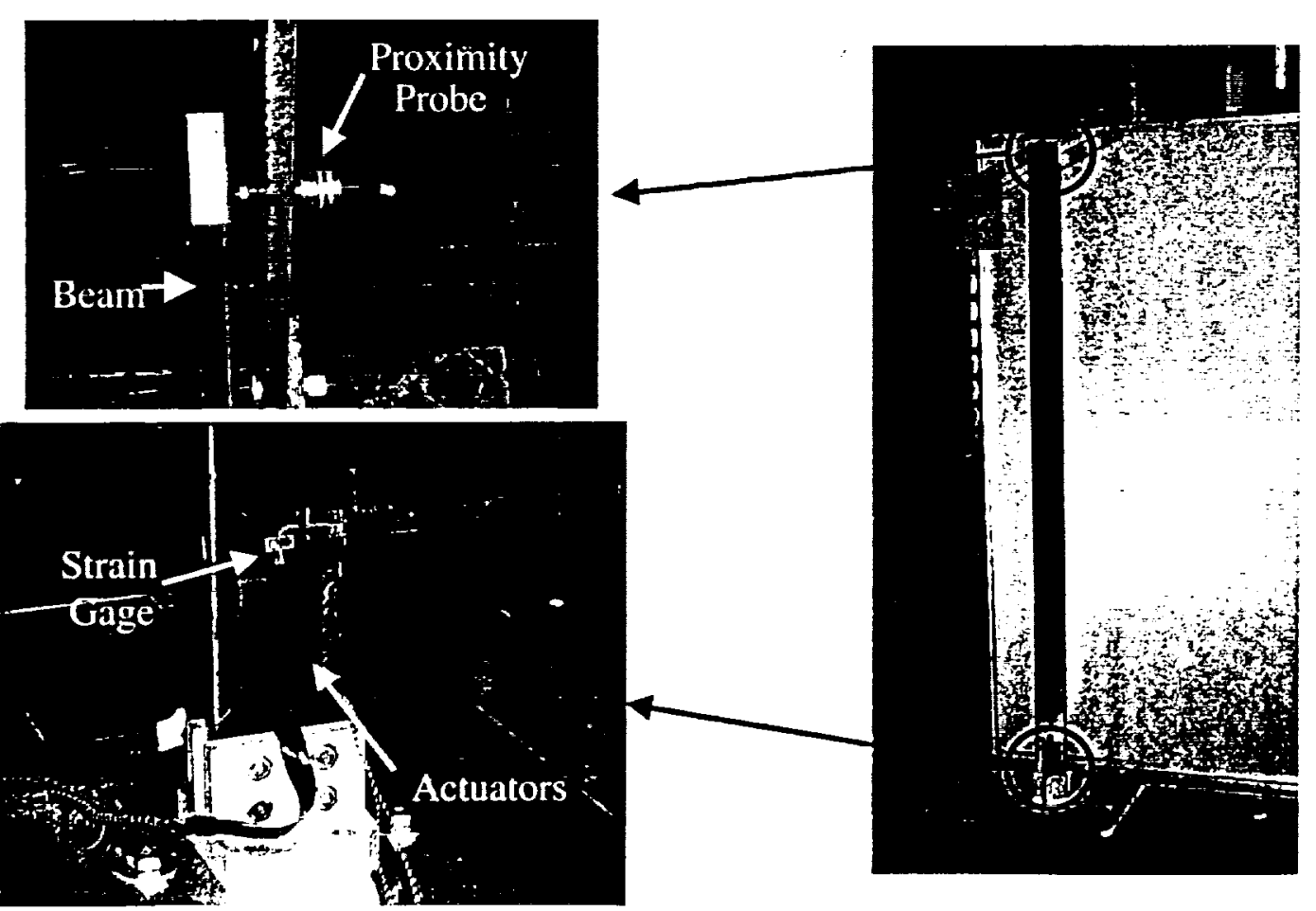

Figure 2b. Instrumented Composite Box Beam Test article. 


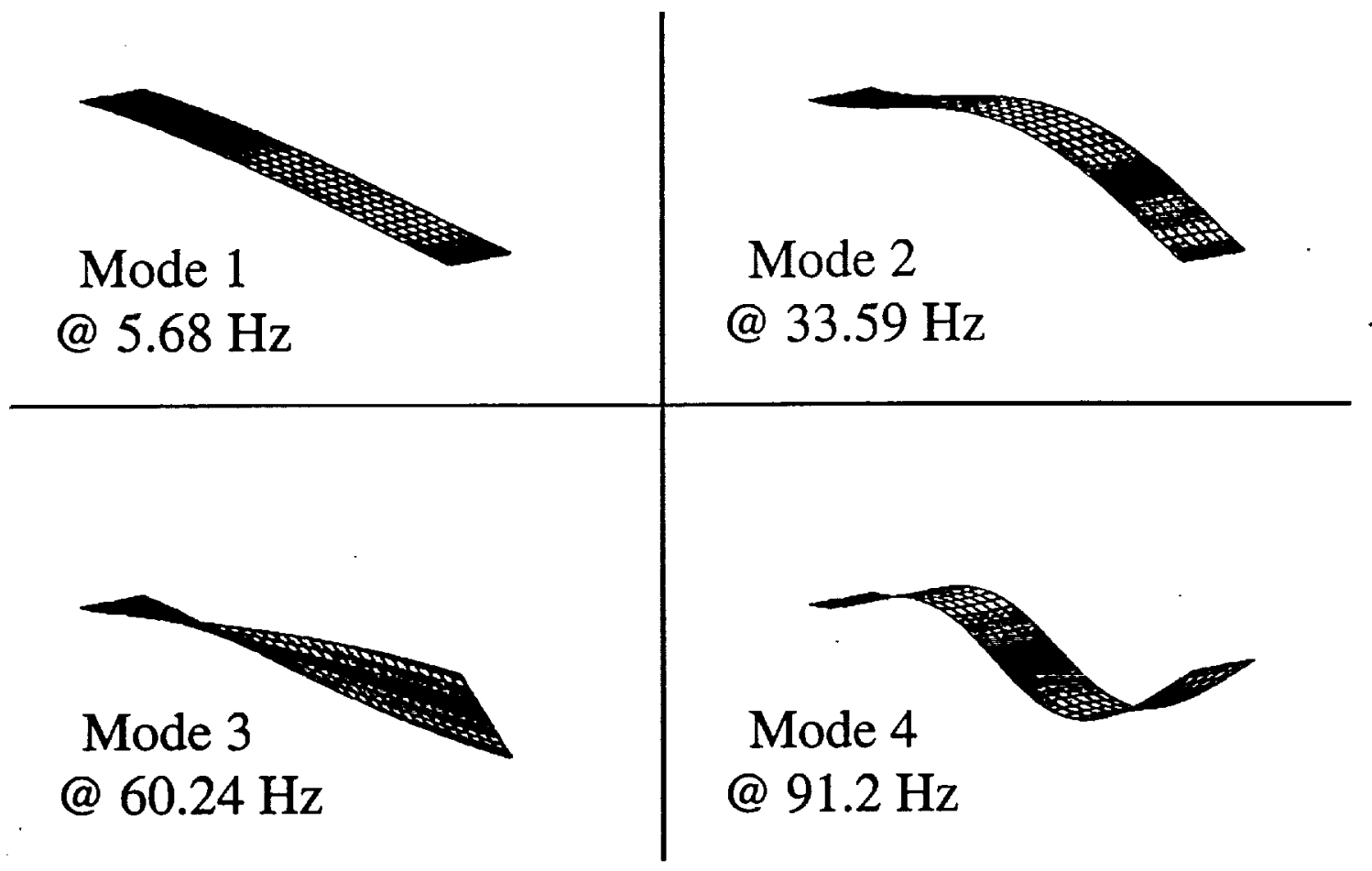

Figure 3. Mode shapes of aluminum beam with piezoelectric actuator.
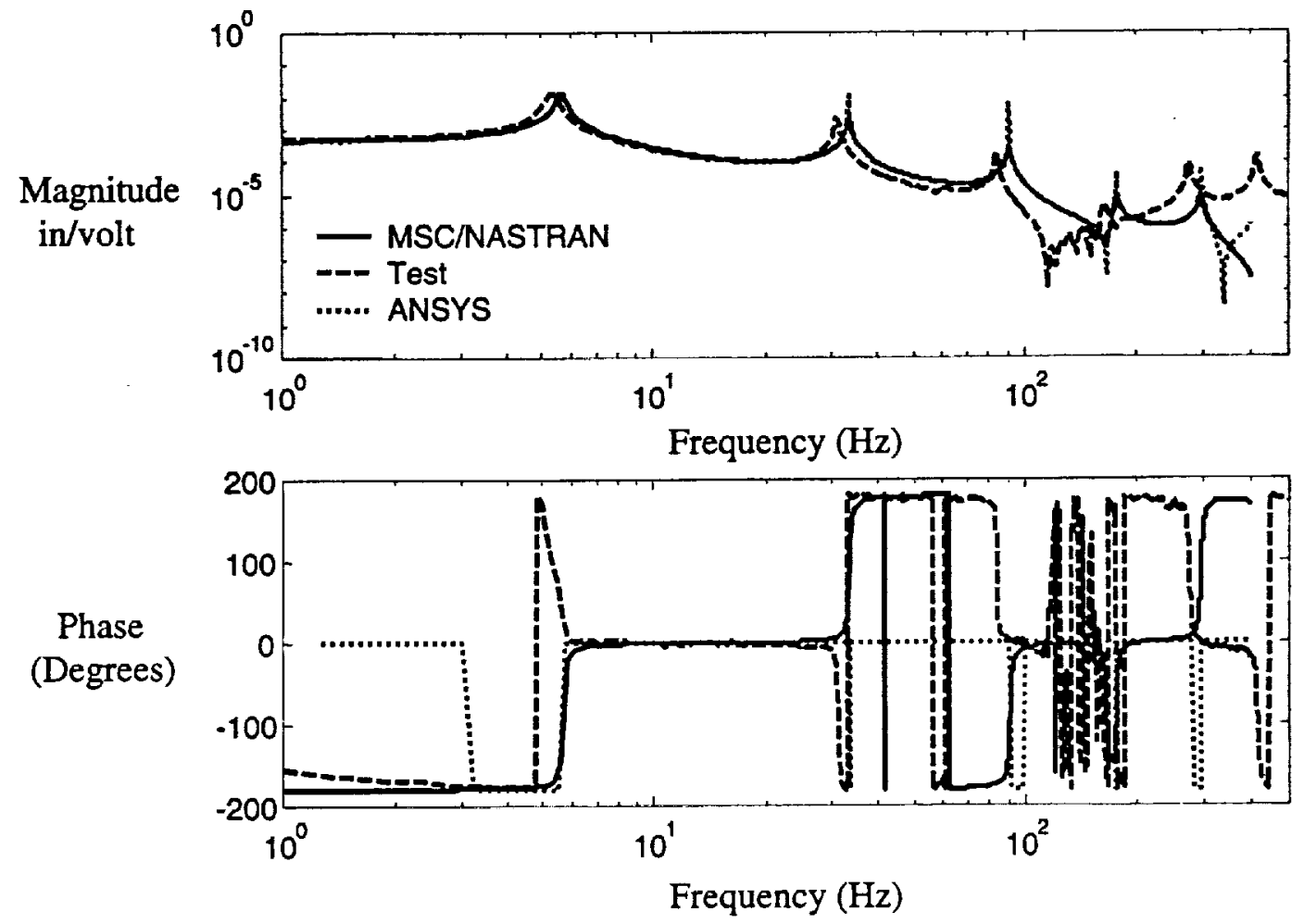

Figure 4. FRF of aluminum test article tip displacement as a function of piezoelectric actuator input voltage. 

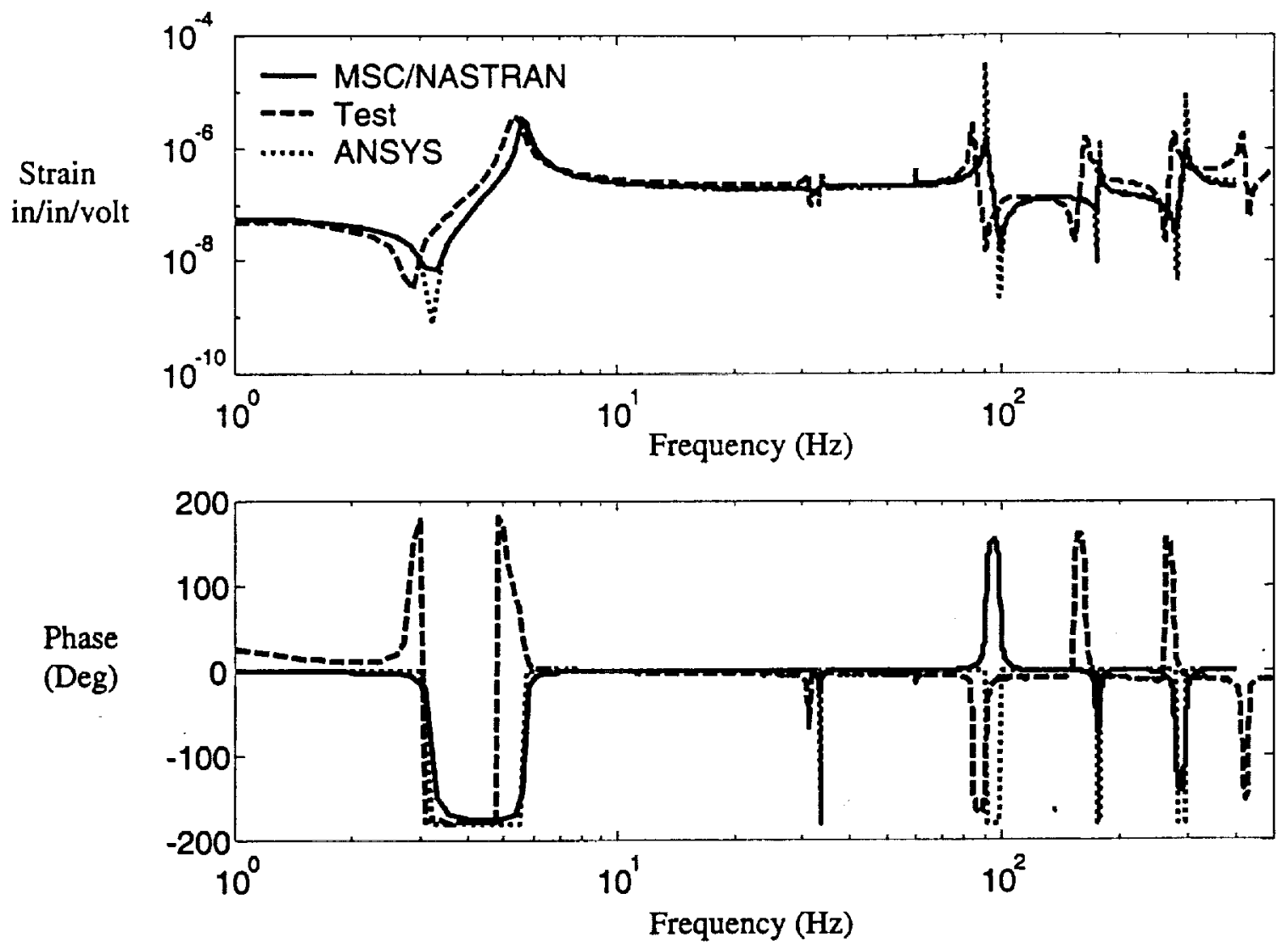

Figure 5. FRF of Aluminum test article strain gage output as a function of piezoelectric actuator input voltage.
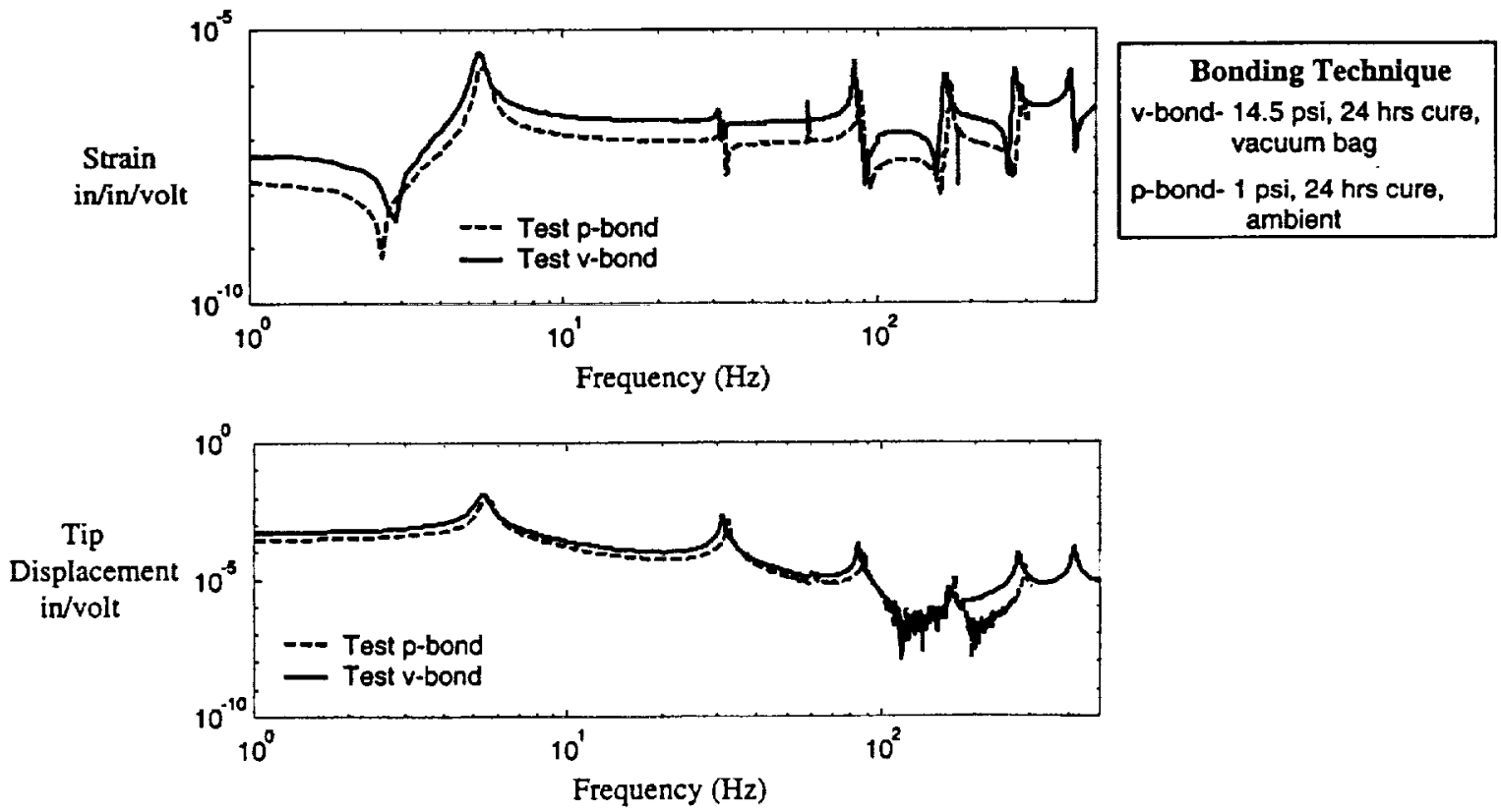

Figure 6. Comparison of actuator effectiveness on aluminum test article. 


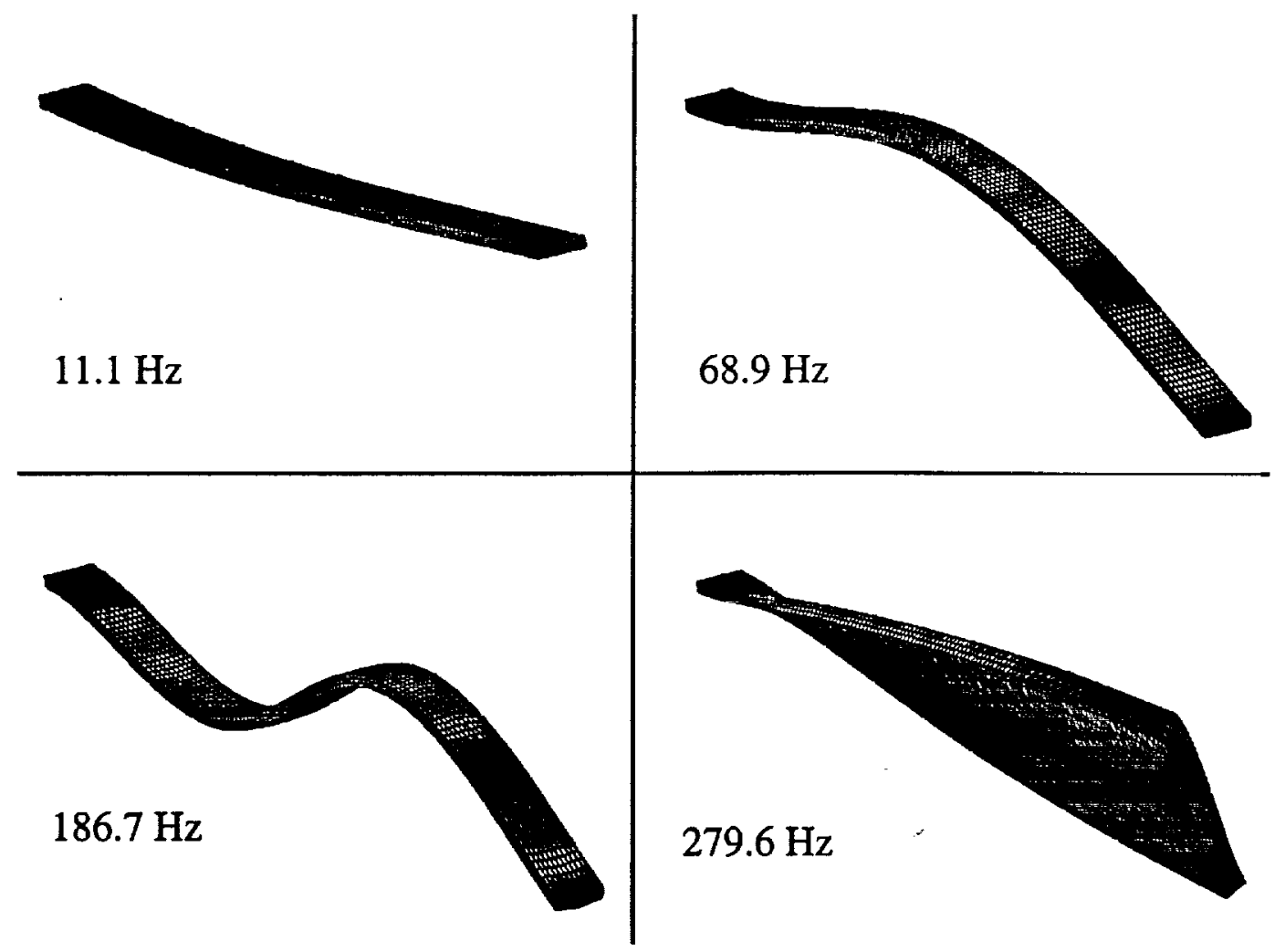

Figure 7. Mode shapes of composite box beam with piezoelectric actuator.
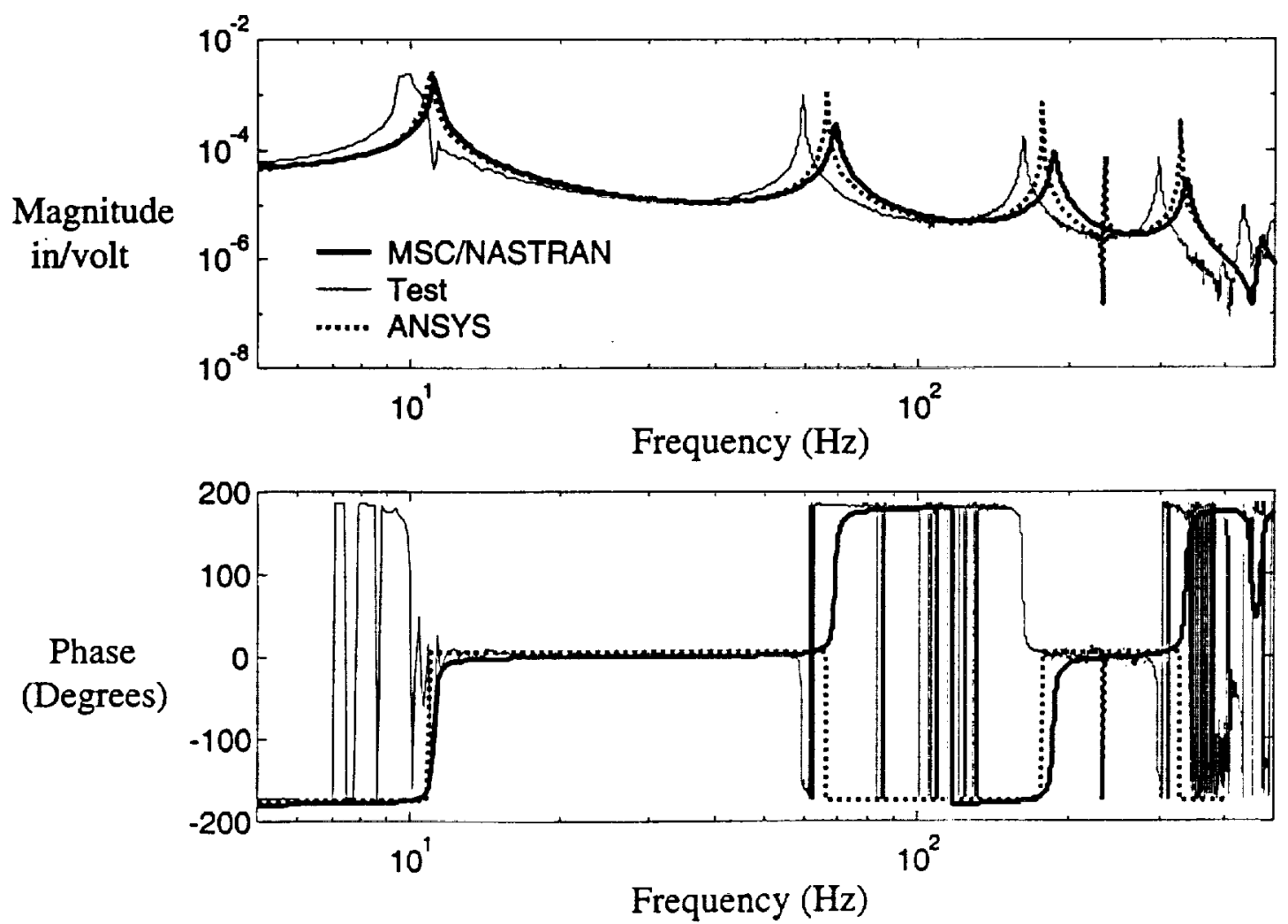

Figure 8. FRF of box beam tip displacement as a function of piezo actuator input voltage. 

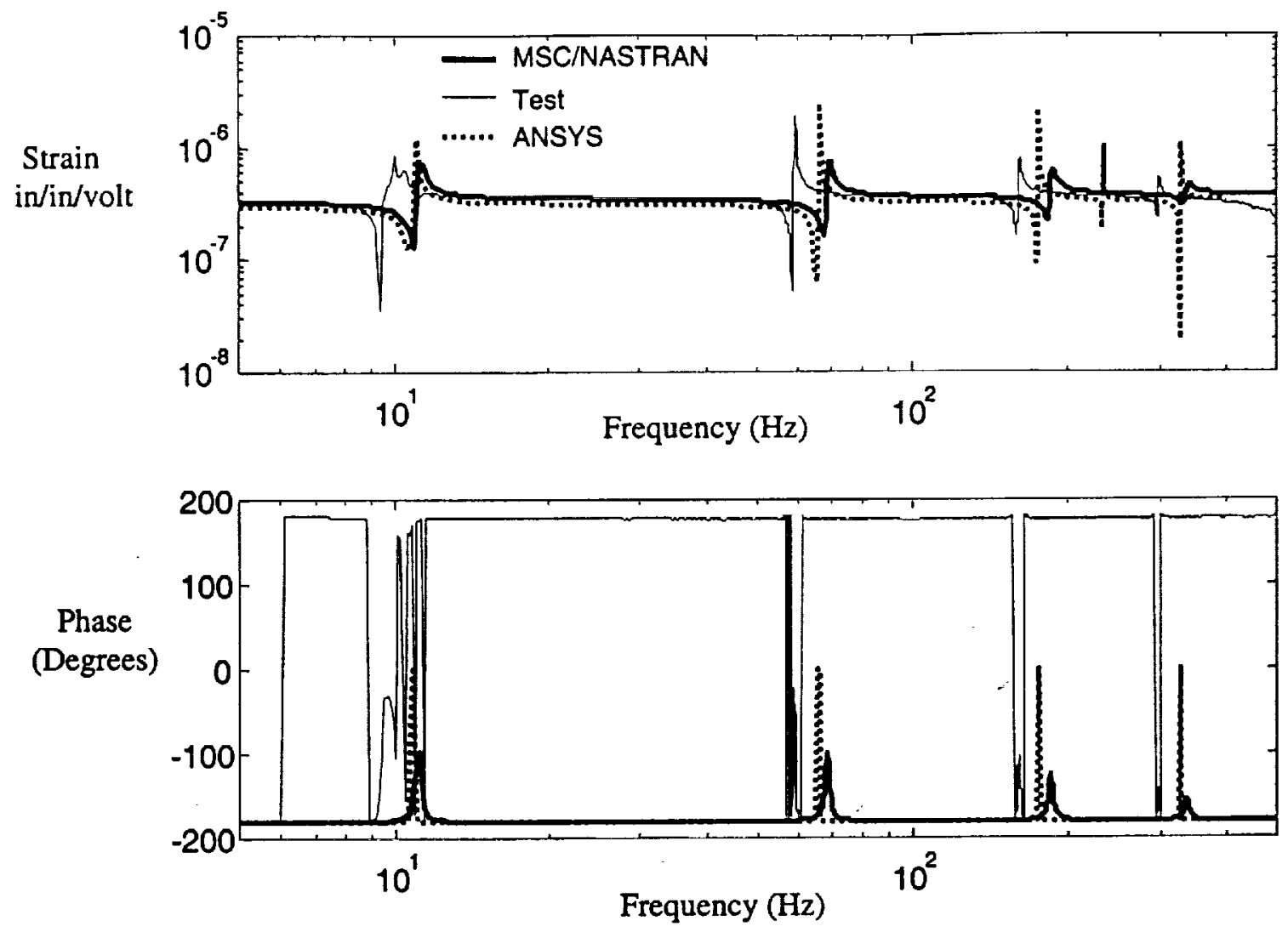

Figure 9. FRF of box beam strain gage output as a function of piezo actuator input voltage. 